\title{
Dynamic effects of insect herbivory and climate on tundra shrub growth: roles of browsing and ramet age
}

\author{
Risto Virtanen ${ }^{1}$, Adam Clark ${ }^{2}$, Michael den Herder $^{3}$, and Heikki Roininen ${ }^{4}$ \\ ${ }^{1}$ University of Oulu \\ ${ }^{2}$ German Centre for Integrative Biodiversity Research (iDiv) Halle-Jena-Leipzig \\ ${ }^{3}$ European Forest Institute \\ ${ }^{4}$ University of Eastern Finland
}

April 28, 2020

\begin{abstract}
To predict plant responses under climate change, we need to understand how thermal conditions and herbivory contribute to shoot growth. Here, we used empirical dynamic modelling (EDM) to analyse an 18-year time series from an experimental system at the forest-tundra ecotone to identify relationships between growth, climate, insect herbivores, browsers and ramet age. We found that negative effects of insect herbivory on willow shoot growth are intensified during warmer years. Moreover, the negative effect of insect herbivores was moderated by ramet age, but this moderation was only realized in the absence of vertebrate herbivores - under browsing by both ptarmigans and reindeer, the positive effects of ramet age were eliminated. Jointly, these results demonstrate the context-dependent and dynamic effects of climate and multiple herbivores on shoot growth, and improve our ability to predict effects of climatic warming in arctic environments.
\end{abstract}

\section{Introduction}

Climatic constraints limit annual growth of woody plants in cold high-latitude environments (Havström et al . 1993; Myers-Smithet al . 2015; Weijers et al . 2018). The growth of tundra shrubs positively correlates with warmer summer thermal conditions (Pajunen 2009; Forbes et al . 2010; Li et al . 2016; Ackerman et al . 2018), implying that under warming conditions shrub growth will increase (Myers-Smith et al . 2015). On the other hand, broad-scale insect outbreaks causing defoliations of most deciduous woody plants are becoming more frequent (Jepsen et al . 2008; Tenow et al . 2004; Lund et al . 2017; Svenssonet al . 2018). Defoliations have been associated with reductions in growth (Crawley 1983, 1989; Hoogesteger \& Karlsson 1992; Takahashi \& Huntly 2010; Wilmking et al . 2012). The browsing of vertebrate herbivores also reduces woody plant growth in various environments (Post \& Pedersen 2008; Newton et al . 2014, Vuorinen et al . 2020). At high latitudes, reindeer browsing has been found to reduce flowering and survival of entire ramets (i.e. a clonal colony or a group of genetically identical plants) or their parts (den Herder et al . 2004; Hakkarainen et al . 2007; Ravolainen et al . 2014) and long-term browsing reduces the abundance of willows (Pajunenet al . 2008, 2012, Kitti et al . 2009; Ravolainen et al . 2011). In addition, browsing by willow ptarmigan has been found to increase shoot dieback and constrain ramet growth (Hakkarainen et al . 2007; den Herder et al . 2008; Tape et al . 2010; Christie et al . 2014).

The effects of climatic factors and herbivory on growth dynamics of tundra shrubs is of growing research interest (Christie et al . 2015; Martin et al . 2017). Here a key unresolved question concerns teasing apart dynamic effects of herbivory and warming climate on willow growth. While there is experimental and observational evidence that warmer conditions are associated with higher levels of herbivory (Roy et al . 2004; Birkemoe et al . 2016; Barrio et al . 2017; Lehmann et al . 2020), it is infrequently documented that herbivory 
can counteract positive climate effects on plant growth (but see O'Connor 2009; Vuorinen et al . 2020). Such possible antagonistic effects of climate warming and herbivory on plant growth are further complicated by the moderating effects of plant age or browsing pressure affecting meristem activity and growth (Wijk 1986; Massad 2013). Thus, it is important when investigating the dynamic effects of insect herbivores and climate on plant growth, it is also necessary to consider plant age and browsing pressure.

The current pressing questions concern shrub growth under climatic and non-climatic drivers (Myers-Smith et al . 2015). In this study we conduct a model-based analysis of long-term shoot growth of a tundra willow, and test how it is linked to variation in thermal conditions, insect herbivory, vertebrate browsing and plant age. In particular, we hypothesized that higher temperatures in the growing season would promote shoot growth, while intensifying insect herbivory would counteract the effects of warming conditions on shoot growth. We further expected that plant age and vertebrate browsing could moderate both climatic and insect herbivore effects on shoot growth. We quantified the joint dynamic effects of insect herbivory and thermal conditions on shoot growth using empirical dynamic modelling (EDM), a recently developed method which can quantify the strength and direction of interactions in observational time series data, even when these interactions vary through time. Using these techniques, we succeeded in identifying dynamic effects of climate and herbivory on plant shoot growth in an 18-year time-series data from a browser-exclusion experiment in NW Finnish Lapland. Moreover, our analyses reveal that plant-herbivore interactions vary greatly with ecological context, including differences among experimental treatments manipulating browsing pressure (fences) and plant age (rejuvenation by pruning treatment).

\section{Material and methods}

The study area is located in NW Finnish Lapland at a transitional area between boreal mountain birch forests and treeless oroarctic and arctic tundra heaths at higher elevations (Virtanen et al . 2016). The study site lies at an elevation of $550-570 \mathrm{~m}$ a.s.l. $\left(68.92^{\circ} \mathrm{N}, 20.97^{\circ} \mathrm{E}\right)$. In this landscape, tundra-like vegetation occurs also in valleys with frost-hummocky dwarf birch (Betula nana) heath with some willows and mountain birch (Betula pubescens ssp.czerepanovii), and moss and lichen dominated ground-layer. In the study area, tea-leaved willow (Salix phylicifolia) is a common shrub that is generally regarded as palatable, and is browsed by several vertebrate species. Willow ptarmigan (Lagopus lagopus ) browses willows primarily in winter when willow shoots and buds reach above snow level. Reindeer (Rangifer tarandus ) browse willow by ripping leaves and shoots primarily in early summer. In the study area, reindeer are semi-domesticated and have had relatively high stocking rates of c. 10 ind $/ \mathrm{km}^{2}$. The study area was a summer reindeer range until 2008, after which reindeer were moved to another area for the summer season. Therefore, in 2008-2018 only solitary reindeer were seen in the area in summer-time. Mountain hare (Lepus timidus) browsing has been very infrequent in the study area, as well as that of Norway lemmings (Lemmus lemmus) and voles (Microtus oeconomus, Myodes rufocanus. Peaks of vole and lemming populations occurred in 2009-2010 and 2014-2015. In our study area we have observed two main folivorous insect herbivores that defoliate leaves partly or completely. One is autumnal moth (Epirrita autumnata) that feeds on the willow during population outbreaks and can cause complete defoliation of willows. Outbreaks of autumnal moth defoliating willows occurred in 2003-2005 and 2011-2013. The other are folivorous beetles (mainly Gonioctena spp.; Chrysomelidae) that have been observed in most years.

\section{Experimental design}

Eighty willow genets in two forest-tundra ecotone sites were selected for the experiment in 1997. In these sites, the genets were selected within areas of c. $50 \times 200 \mathrm{~m}$ and $50 \times 250 \mathrm{~m}$. Genets were $30-50 \mathrm{~cm}$ tall and consisted of 10-25 ramets each. All genets were initially accessible to both reindeer and ptarmigan. The genets were then assigned into blocks of four genets. In 1997-1998, two random genets within each block were rejuvenated by pruning ramets five $\mathrm{cm}$ above the ground level. The pruned genets produced sprouts that initially grew vigorously for 1-3 years and within a few years reached the size of unpruned genets. Thus, each block consisted of two old genets and two rejuvenated genets. Within each block one of the old and rejuvenated genets were protected by reindeer fences $(2 \times 2 \mathrm{~m}$ area). In 2000 , reindeer fences were replaced by ptarmigan proof fences in half of the blocks, selected at random. The experimental design from 2000 
onwards included treatment combinations of reindeer exclusion and reindeer + ptarmigan exclusion on both old and rejuvenated genets (see Table 1, Supporting Information).

Table 1. The experimental design of the long-term browsing experiment. Reindeer exclusion $(-)$ consists of experimental units with reindeer fence, whereas ptarmigan and reindeer browsing exclusion treatments (-) have fences with $3.5 \mathrm{~cm}$ mesh size. Rejuvenated $(+)$ treatments were initially pruned above ground level.

\begin{tabular}{lllll}
\hline Treatment & Reindeer & Willow ptarmigan & Rejuvenation & Abbreviation \\
\hline Reindeer + ptarmigan browsing + rejuvenation & + & + & + & RPJ \\
Reindeer + ptarmigan browsing & + & + & - & RP \\
Ptarmigan browsing + rejuvenation & - & + & + & PJ \\
Ptarmigan browsing & - & + & - & $\mathrm{P}$ \\
Rejuvenation & - & - & + & $\mathrm{J}$ \\
None & - & - & - & $\mathrm{N}$ \\
\hline
\end{tabular}

In summer 2001, four willow ramets of each genet were tagged with basal plastic slips. The shoot growth of tagged ramets was monitored every year. The shoot lengths of each tagged willow ramet were measured in early August (at the end of the active growing season) to an accuracy of $0.5 \mathrm{~cm}$. In cases where an individual ramets died, a new ramet of the same genet were tagged. Initially, 320 ramets were tagged in 2001, while the total number of individual ramets tagged was 626 . In addition, the level of insect herbivory was estimated using the following defoliation classes: 0 no observable insect herbivory, $1(0-1 \%), 2(1-5 \%), 3(6-25 \%), 4$ $(25-100 \%)$ or 5 (leaves totally defoliated) (den Herderet al . 2004). Herbivory shows remarkable among-year variation in 2001-2018, but no trend (Supporting Information).

Climate data were obtained from the nearest Finnish Meteorological Institute weather station (Kilpisjärvi Kyläkeskus) located $10 \mathrm{~km}$ from the experimental site (480 m a.s.l.). The weather station provides daily records on mean temperature. These climatic station data were used to calculate thermal sum for the season, when shoot growth takes place. Therefore, daily mean temperatures exceeding $+5{ }^{\circ} \mathrm{C}$ in May-July were summed up to produce a "growing degree days - GDD" index, hereafter denoted as Climate. Thermal sum shows remarkable among-year variation in 2001-2018, but no clear trend (Supporting Information). Note that although there are many other potential climate-related variables that we could have considered (e.g. length of growing season, growing degree days with different threshold, mean July temperature), these all correlated with the thermal sum as described above - we therefore chose to only consider this commonly used variable in our analyses.

Empirical dynamic modelling

We used EDM to model the relationships between willow shoot growth, climate and herbivory. EDM is a recently developed technique that combines two tools (Deyle et al . 2016)-convergent cross mapping (CCM) and sequential locally weighted global linear maps (S-mapping). CCM is a nonparametric method for tracking information flow among variables, and is a powerful tool for identifying causal links in systems with complex dynamics (Sugihara et al . 2012; Clarket al . 2015). Because the direction of information flow is directional in causal interactions (i.e. "forcing" processes impart information onto "response" processes, whereas the reverse is not true), CCM is also often successful at identifying the direction of causal interactions based on observational data. S-mapping is a related technique that can be used to extract information about the strength and direction of these relationships (Sugihara 1994). These methods are particularly useful for our purposes, as they can be applied without a priori knowledge of the functional form of the relationship governing interactions and apply even for highly complex or chaotic dynamics. They also provide two major advantages over more classic methods, such as mixed-effects linear models or GLM's. First, in complex ecological systems, results from CCM tend to be more closely aligned with actual causal forcing than is true for regression (Sugiharaet al . 2012; Clark et al . 2015). This feature allows us to generate putative interaction networks among species based on observational data. Second, S-mapping captures effects of 
dynamic, nonlinear relationships among variables. Thus, S-mapping allows us to analyse the strength and direction of interactions among species even when they are complex, time-varying, and context dependent. The analyses were employed using rEDM package and EDMhelper packages in R (Yeet al . 2018; Karakoç et al . 2020).

Based on a time-delayed application of Convergent Cross Mapping (CCM) (Fig. 1), we chose to quantify effects of climate (Climate) and insect herbivory (Herbivory) on mean shoot length of topmost part of the ramets (Shoot). In CCM analysis, causal forcing is indicated when predictive skill increases significantly with the total number of historical observations used to make predictions (i.e. "library length"). We identified significant forcing of ramet dynamics by both climate and herbivory (Fig 1). Because multi-trophic interactions often involve time-delayed effects, we tested for both immediate and lagged effects. Analyses suggested that effects of insect herbivores on shoot growth were immediate (i.e. time-lag $=0$ ), whereas climate was best represented by a time-lagged effect (time-lag $=-1$ ). All variables were standardised to zero mean and unit standard deviation before analysis, to better allow for comparison of effect sizes among variables. Note that although "best practices" dictate that 30-40 sequential observations are usually necessary for CCM and, to a lesser extent, S-mapping, this limit can be met either by single long time series, or using composites that have been stitched together from multiple shorter time series (Hsieh et al . 2008; Clark et al . 2015). For all analyses presented here, within each treatment, time-series from all ramets and replicates were stitched together, resulting in time series of $>640$ measurements for each treatment. 

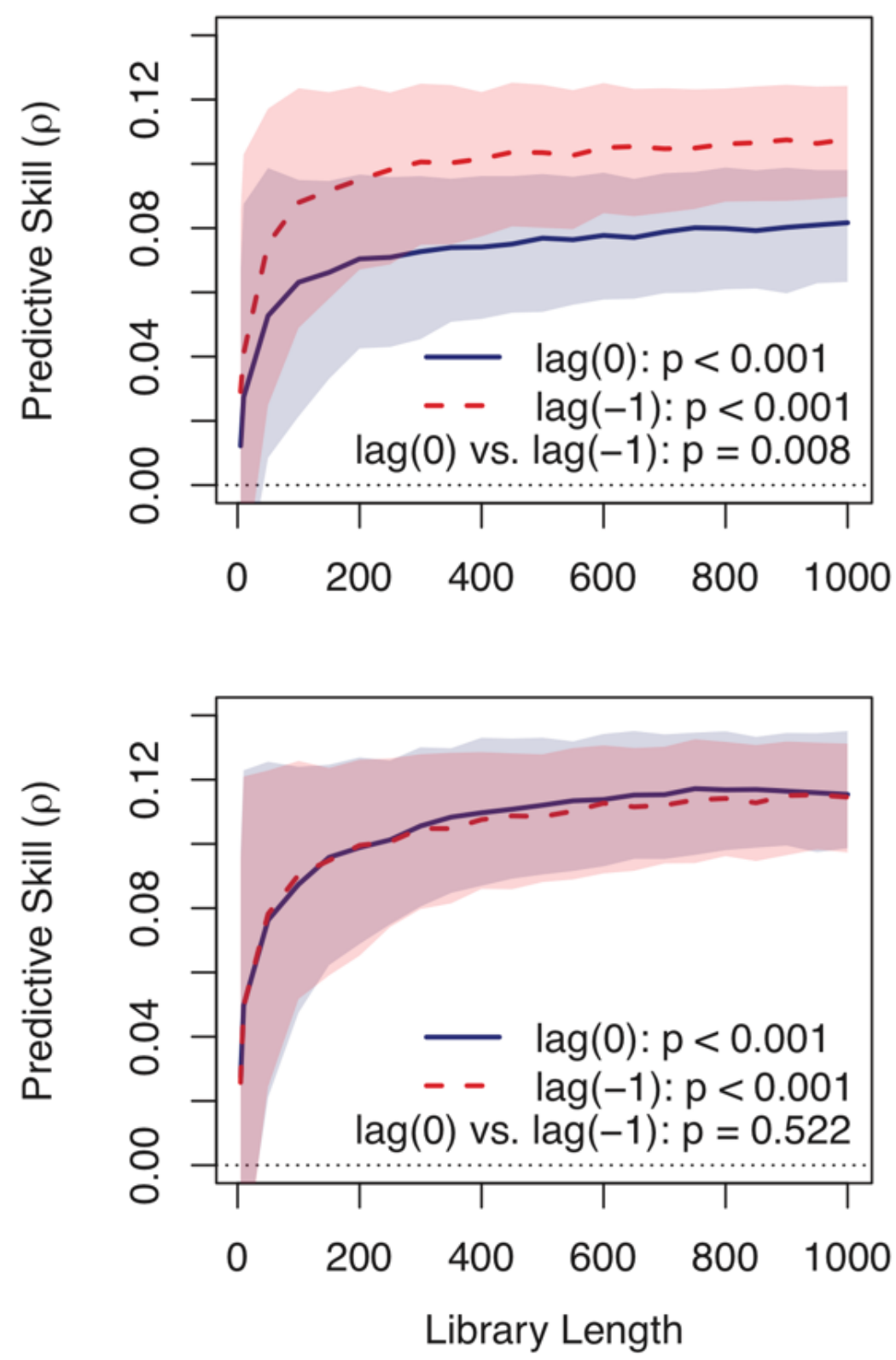

Figure 1. CCM results of mean shoot length vs. growing degree days (measured May - July) and insect herbivory. Prediction skill is measured as Pearson's correlation coefficient. Significant causal forcing is indicated in cases where prediction skill increases significantly with library length. P-values indicate significant increase in prediction skill for the longest library length tested relative to the shortest library length tested at lag $=0$ and lag $=1$, respectively, as well as a comparison of the predictive skills for lag $=0$ vs. lag $=1$.

Using this information, we found that the best embeddings (i.e. predictive models) of system dynamics were achieved using four time-lagged dimensions, and a tuning parameter that indicated moderately nonlinear dynamics $(\vartheta=0.75)$. To construct a predictive model of willow shoot growth dynamics as a function of the 
full set of causally related variables, we therefore used two lagged dimensions of willow shoot lengths, one lagged dimension of climate, and one non-lagged dimension of insect herbivory. These relationships yielded a model of the form:

mean_shoot $(t+1)=\beta_{0}+\beta_{1}$ Shoot $(t)+\beta_{2}$ Shoot $(t-1)+\beta_{3}$ Climate $(t-1)+\beta_{4}$ Herbivory $(t)$

where $\beta_{l}$ indicates fitted values, which are allowed to vary through state-space based on historical dynamics. For example, $\beta_{1}$ might be high for low values ofmean_shoot $(t)$, indicating that increases in shoot biomass also lead to increases in growth, whereas it might be low for larger values of mean_shoot $(t)$, indicating self-limitation.

In general, the fitted parameters $\beta_{3}$ and $\beta_{4}$ can be interpreted as partial derivatives describing the effect of thermal climate and insect herbivory on shoot growth (i.e. [?] Shoot /[?] Climate and [?]Shoot /[?] Herbivory , respectively). Positive values indicate that shoot growth increases as a function of warmer climate or higher insect herbivory. Negative values indicate that growth declines with warming, or declines with increased insect herbivory. Note that these can be interpreted identically to slopes in a standard linear regression (e.g. where the slope term describes the partial derivative of response variable $y$ relative to explanatory variable $x,[?] y /[?] x)$.

\section{Results}

When considered across all experimental treatments (Fig. 2), we find evidence for negative effects of insect herbivory on willow shoot growth, and for a mix of negative and positive effects of climate (Fig. 2a). These climate effects generally became more positive with warming, such that at cool climate conditions (low GDD), warming climate conditions were associated with declines in shoot growth, whereas under warmer conditions, further warming had either no effect, or weakly positive effects (Fig. 2b). The joint outcome of these patterns was that under cooler climate conditions, insect herbivores had relatively weak effects on willow shoot growth, whereas under warmer conditions, the negative effects of insect herbivory on shoot growth became more pronounced (Fig. 2c).

\section{Hosted file}

image2 . emf available at https://authorea.com/users/308015/articles/439003-dynamic-effects-ofinsect-herbivory-and-climate-on-tundra-shrub-growth-roles-of-browsing-and-ramet-age

Figure 2. Estimated interaction strengths from S-mapping analysis, based on pooled data including all experimental treatments. Points show results for individual time steps, whereas lines show mean \pm one standard deviation. Recall that partial derivatives can be interpreted in the same way as the slope of a linear regression - i.e. [?] $y$ /[?] $x$ describes the slope of a regression of $y$ as a function of $x$. (A) Estimated effect of herbivory on shoot growth, vs. estimated effect of climate on shoot growth for a time lag of -1 . Note that cases with more positive effects of climate are associated with more negative effects of insect herbivory. (B)Estimated effect of climate on shoot growth, vs. time-lagged climate (GDD). Note that warmer years are associated with a more positive effect of climate on shoot length. (C) Estimated effect of insect herbivory on shoot growth, vs. time-lagged climate (GDD). Note that in warmer years, negative effect of insect herbivory is intensified. 


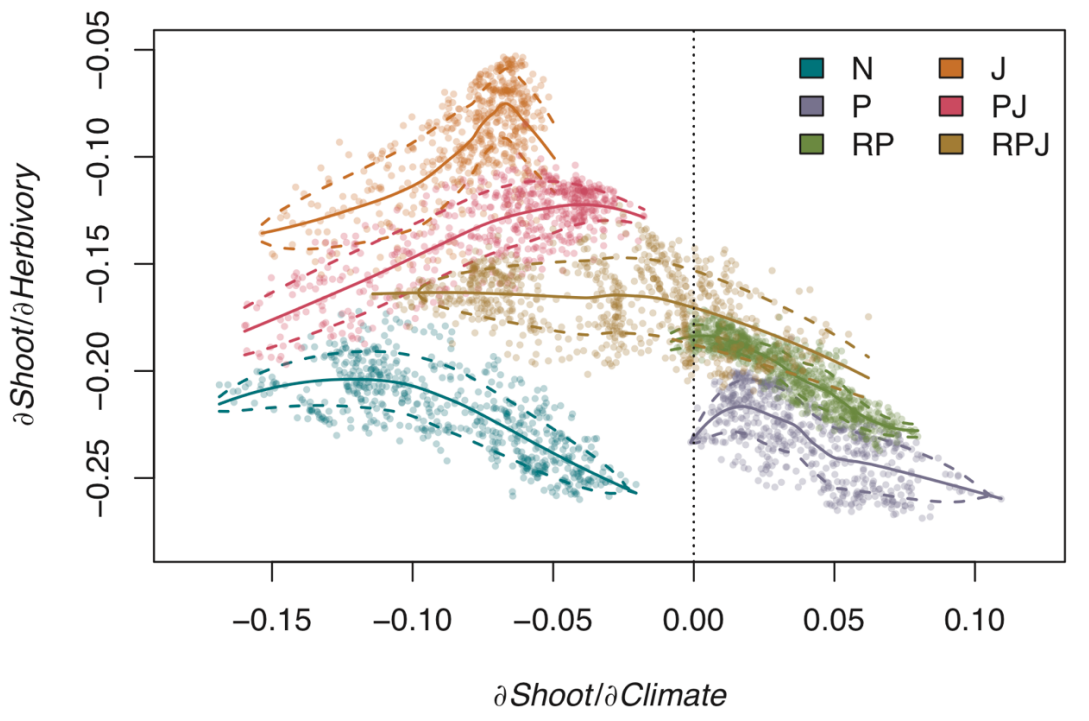

Figure 3. Relationship between climate effects on willow shoot growth, and effects of insect herbivores on shoot growth. Tests are the same as those in Fig. 2a, except that analyses are run separately for each of the experimental treatments. Abbreviations indicate: no vertebrate herbivores $(N)$; only herbivory by ptarmigans $(P)$, herbivory by ptarmigans and reindeer $(R P)$, and the interaction of each of these treatments with "rejuvenation" (i.e. pruning of shoots in year 1 of the experiment) $(J, P J$, and $R P J$, respectively) (Table 1).

When separated by browsing and rejuvenation treatments, we found that the general pattern of responses of willow shoot growth to climate and insect herbivores was similar to that in our pooled analysis (Fig. 3, compare to Fig. 2a). However, the test revealed that the treatments differ and that relationships within treatments were not uniform. Recall that there are six different experimental treatments: neither vertebrate herbivores $(N)$; only herbivory by ptarmigans $(P)$, herbivory by ptarmigans and reindeer $(R P)$, rejuvenation (i.e. pruning of shoots at the initiation of the experiment) $(J)$, rejuvenation plus browsing by ptarmigans $(P J)$, and rejuvenation plus browsing by ptarmigans and reindeer $(R P J)$. For most treatments, there was still a negative relationship between the effects of climate and the effects of insect herbivory, except in the case of rejuvenation treatments, for which the relationship reversed (J, PJ treatments in Fig. 3). Additionally, the treatments that included vertebrate herbivores tended to experience more positive effects of climate on shoot growth, while for treatments that included rejuvenation, herbivory effects were generally less negative (compare treatments $\mathrm{P}$ vs. PJ, RP vs. RPJ in Fig. 3). 
N

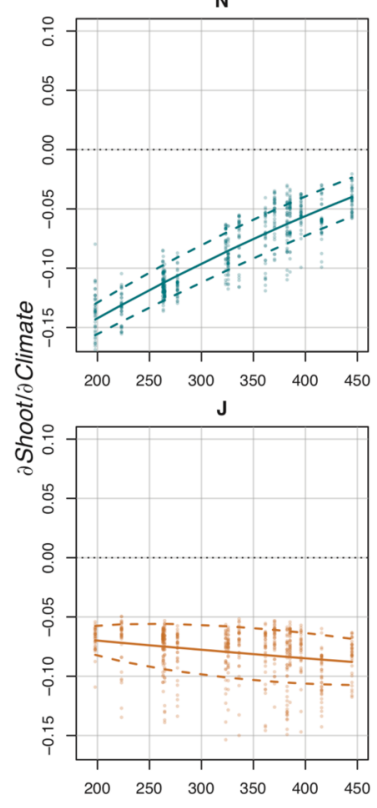

$P$

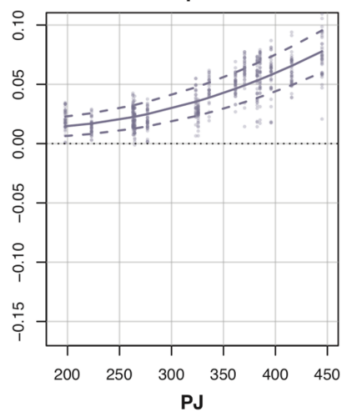

PJ

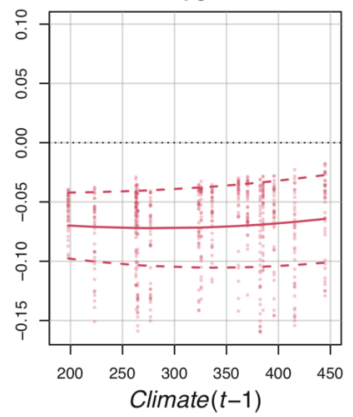

RP

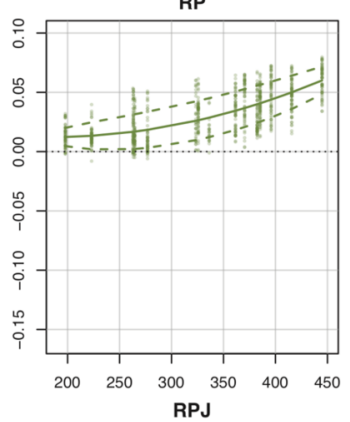

RPJ

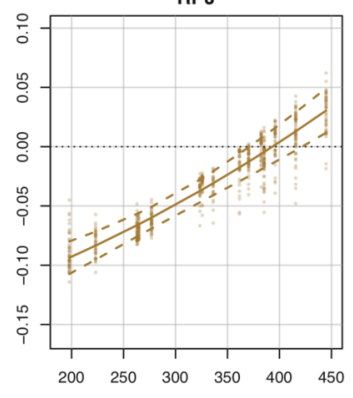

Figure 4. Relationship between climate effects on willow shoot growth, and lagged climate. Tests are the same as those shown in Fig. 2b, except that analyses are run separately for each of the experimental treatments. Abbreviations are as described in the legend to Fig. 3 and in Table 1.

The effects of climate on shoot growth were also similar across treatments, generally with a positive relationship between climate effects and growing degree days (Fig. 4). Recall that negative climate effects suggest that warming will have a negative impact on shoot growth, whereas positive effects suggest that warming leads to increases in shoot growth - our results therefore suggest that at low temperatures, warming will have an overall negative effect on growth, whereas at higher temperatures, warming will have an overall positive effect. Interestingly, treatments that included vertebrate herbivores and no rejuvenation $(P, R P)$ tended to experience more positive effects of climate, such that the effect was consistent over a range of previous year thermal conditions. In contrast, rejuvenation treatments tended to suppress the positive relationship between climate and climate effects, such that there was a fixed, negative effect of climate regardless of growing degree days. However, for the treatment that included both vertebrate herbivores and rejuvenation, the positive relationship returned, and the overall pattern was similar to that for shoot growth in conditions without browsers $(N)$. 

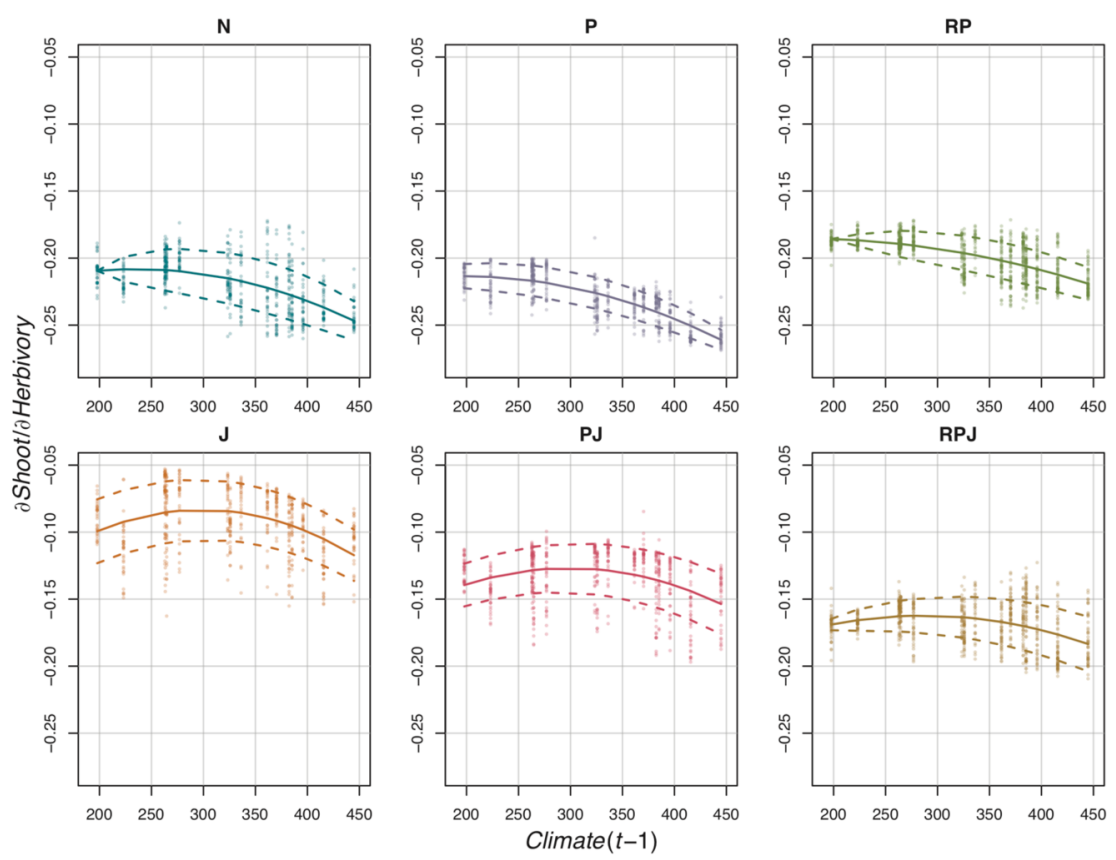

Figure 5. Relationship between insect herbivore effects on willow shoot growth, and lagged climate. Tests are the same as those in Fig. 2c, except that analyses are run separately for each of the experimental treatments. Abbreviations are as described in the legend to Fig. 3 and Table 1.

The joint outcome of these patterns again led to negative relationships between effects of insect herbivory and climate, such that insects had more strongly negative effects in warmer years. Interestingly, while vertebrate herbivory alone had little impact on this trend (i.e. $P, R P$ ), negative effects of herbivory appeared to be buffered by rejuvenation treatments, such that the overall effect of insect herbivores was smaller (e.g. $J$, $P J)$ (Fig. 5). Again, however, this buffering appeared to be nullified by vertebrate herbivory, such that the treatment that included both vertebrate herbivores and rejuvenation $(R P J)$ showed a response that was roughly identical to that in the untreated experimental unit $(N)$.

\section{Discussion}

Our results based on EDM modelling provide several new insights on joint effects of insect herbivory and climate as drivers of annual willow growth. First, our results support the prediction that negative effects of insect herbivory on shoot growth intensify along with effects of warmer conditions of growing season. However, contrary to our expectation, the effects of warming summer conditions on annual shoot growth were generally, on net, negative, although effects tended to become either less negative or weakly positive under warmer conditions, especially in experimental treatments that included vertebrate herbivores. Second, supporting our expectations, dynamic effects of insect herbivory and climate on shoot growth depend on vertebrate browsing and ramet age. In particular, the negative impact of insect herbivory is weaker on young ramets, while vertebrate browsing tended to enhance insect herbivory effects. Jointly, these results from a long-term experiment and EDM markedly advance our understanding of context-dependent effects of climate and herbivory on shrub growth at forest-tundra ecotones.

The finding that the negative effect of insect herbivory on shoot growth becomes more intense under warmer climates provides support for earlier studies suggesting that at more northerly latitudes, higher summer temperatures extend the summer season and increase the thermal budget for growth and reproduction insect herbivores, and it could result in increasing herbivory (Bale et al . 2002; see also Lehmann et al . 2020). It is also compatible with findings from an experimental system, in which O'Connor (2009) found that increasing 
temperature increased per capita interaction strength between macroalgae and their grazers, and reversed positive effects of temperature on plant growth. Barrio et al . (2016), however, found that a cold-adapted caterpillar performed worse under warmer conditions in the tundra. Therefore, it is still uncertain how insect herbivory levels will change under climatic warming as well as to what extent insect herbivory can modify climate-growth relationships.

Our finding of negative effects of warming on shoot growth, at least under cooler conditions, although somewhat counter-intuitive, could potentially be a result of the net balance between increasing respiration costs vs. faster overall growth and photosynthetic rates. Although photosynthesis rates generally increase faster than tissue growth rates - leading to an overall positive increase in growth with temperature - these changes depend strongly on the timing of the warming and the physiology of the plant (Grace et al . 2002). For example, in cropping systems, increased night time temperatures can have strong negative impacts on growth and yield due to a disproportionally large increase in respiration rates (Mohammed \& Tarpley 2008). Similar imbalances would explain why growth under the herbivory treatments was generally bolstered by warming (where growth was presumably focused on edible tissues such as leaves and buds, which also contribute to photosynthesis), whereas warming effects were more strongly negative in the rejuvenation treatments (where growth presumably also included large amounts of structural tissue). Additionally, it is possible that in the coldest soils, root systems have strongly limited nutrient uptake activity (Havraneck 1972; Day et al . 1989) and cold conditions further decrease sink strength (Hoch \& Körner 2003).

Importantly, our EDM analyses of long-term time series data on shoot growth reveal that growth dynamics are not a simple function of summer thermal conditions, but rather are highly context dependent, and vary as a function of herbivory and plant age. Our results are generally compatible with results of the meta-analysis of Arft et al . (1999) who found that deciduous shrubs exhibited weak growth responses to short-term experimental warming. They proposed that deciduous shrubs such as Salix may have a tight control of meristem activity, which may limit their response or ability to respond quickly to warming. Based on our results, we find it likely that vertebrate browsers change meristem activity of buds, and thus either stimulate or inhibit shoot growth and thus influence shoot growth-climate relationships. We find further evidence that young and old ramets differ in their inherent growth dynamics (see also Wijk 1986). In other studies, Vuorinenet al . (2020) found that pine growth reduced at high browsing pressure and warm climate conditions and Marshall et al . (2014) reported that woody vegetation responses to shifts in browsing pressure can depend on plant age. Also, the continuum ontogenetic response model (Massad 2013) predicts that plant herbivore responses can vary depending on plant age. Therefore, there is a growing body of empirical and theoretical evidence pointing out that climate and insect herbivory effects on tundra shrub growth dynamics will necessitate jointly considering both browsing level and age.

Our results have two main implications to current understanding of plant-herbivore interactions under climatic warming. First, these findings seem to challenge a common perspective that temperature is a dominant factor controlling shrub growth at their range edges (Myers-Smith et al . 2015). As our study system is at the edge of the common occurrence of the studied Salix species, we find it possible that effects of herbivory are at strongest at range edges and limit growth of established shrubs. We suspect that this phenomenon is wide-spread but remains rarely documented due to lack of long-term data and dynamic modelling that can link growth and growth regulating drivers. See, however Trotter et al . (2002) and comparable results of Wilmking et al . (2018) reporting Eurois occultaoutbreak effects on Alnus viridis in Greenland and Vuorinenet al . (2020) reporting negative warming effects on pine growth at high deer browsing levels. Second, as has been suggested with regard to vertebrate browsers (Christie et al . 2015) we find it possible that potentially intensifying effects of insect herbivores and their outbreaks (Seidl et al . 2017; Ren et al . 2020), the expansion of deciduous shrub genets is markedly slowed down, while newly established genets and their ramets in warmer and sufficiently enemy free circumstances play the greatest role in the observed tundra shrub expansion.

\section{Acknowledgements}

This research has been supported by grants of Academy of Finland (project \#259072), Maj and Tor Nessling 
Foundation, and University of Oulu Arctic Interactions funding. We thank Matt Ayres for useful comments on the manuscript. We also thank Helena Hakkarainen for assistance in the growth measurements in 2004, and the Metsähallitus and Kilpisjärvi Biological Station for providing logistic support during field work.

\section{Data availability statement}

Data will be made publicly available through open access Dryad Digital Repository.

\section{References}

Ackerman, D. E., Griffin, D., Hobbie, S. E., Popham, K., Jones, E.,et al . (2018). Uniform shrub growth response to June temperature across the North Slope of Alaska. Env. Res. Lett. , 13, 044013.

Arft, A. M., Walker, M. D., Gurevitch, J. E. A., Alatalo, J. M., Bret-Harte, M. S., et al . (1999). Responses of tundra plants to experimental warming: meta-analysis of the international tundra experiment. Ecol. Monogr. , 69, 491-511.

Bale, J. S., Masters, G. J., Hodkinson, I. D., Awmack, C., Bezemer, T. M., et al . (2002). Herbivory in global climate change research: direct effects of rising temperature on insect herbivores. Glob. Ch. Biol. , $8,1-16$.

Barrio, I. C., Bueno, C. G., \& Hik, D. S. (2016). Warming the tundra: reciprocal responses of invertebrate herbivores and plants. Oikos , 125, 20-28.

Barrio, I. C., Linden, E., Te Beest, M., Olofsson, J., Rocha, A.,et al . (2017). Background invertebrate herbivory on dwarf birch (Betula glandulosa-nana complex) increases with temperature and precipitation across the tundra biome. Polar Biol. , 40, 2265-2278.

Birkemoe, T., Bergmann, S., Hasle, T. E., \& Klanderud, K. (2016). Experimental warming increases herbivory by leaf-chewing insects in an alpine plant community. Ecol. Evol. , 6, 6955-6962.

Christie, K. S., Ruess, R. W., Lindberg, M. S., \& Mulder, C. P. (2014). Herbivores influence the growth, reproduction, and morphology of a widespread arctic willow. PloS One, 9, e101716.

Christie, K. S., Bryant, J. P., Gough, L., Ravolainen, V. T., Ruess, R. W., et al . (2015). The role of vertebrate herbivores in regulating shrub expansion in the Arctic: a synthesis.BioScience, biv137.

Clark, A. T., Ye, H., Isbell, F., Deyle, E. R., Cowles, J., et al . (2015). Spatial convergent cross mapping to detect causal relationships from short time series. Ecology , 96, 1174-1181.

Crawley, M. J. (1983). Herbivory. The dynamics of animal-plant interactions. Blackwell Scientific Publications.

Crawley, M. J. (1989). Insect herbivores and plant population dynamics.Annu. Rev. Entomol. , 34, 531-562.

Day, T.A., DeLucia, E.H. \& Smith, W.K. (1989). Influence of cold soil and snow cover on photosynthesis and leaf conductance in two Rocky Mountain conifers. Oecologia , 80, 546-552.

Deyle, E. R., May, R. M., Munch, S. B., \& Sugihara, G. (2016). Tracking and forecasting ecosystem interactions in real time. Proc. R. Soc. B: Biol. Sci. , 283, 20152258.

Forbes, B. C., Macis-Fauria, M. and Zetterberg, P. (2010). Russian Arctic warming and 'greening' are closely tracked by tundra shrub willows. Glob. Ch. Biol. , 16, 1542-1554.

Hakkarainen, H., Virtanen, R., Honkanen, J. O., \& Roininen, H. (2007). Willow bud and shoot foraging by ptarmigan in relation to snow level in NW Finnish Lapland. Polar Biol. , 30, 619-624.

Grace, J., Berninger, F. \& Nagy, L. (2002). Impacts of climate change on the tree line. Annals of Botany , 90, 537-544. 
Havranek, W. (1972). Uber die Bedeutung der Bodentemperatur fur die Photosynthese und Transpiration junger Forstpflanzen und fur die Stoffproduktion and der Waldgrenze. Angerwandte Botanik , 46, 101-116.

Havstrom, M., Callaghan, T. V., \& Jonasson, S. (1993). Differential growth responses of Cassiope tetragona, an arctic dwarf-shrub, to environmental perturbations among three contrasting high-and subarctic sites. Oikos , 66, 389-402.

den Herder, M., Virtanen, R., \& Roininen, H. (2004). Effects of reindeer browsing on tundra willow and its associated insect herbivores.J. Appl. Ecol. , 41, 870-879.

den Herder, M., Virtanen, R., \& Roininen, H. (2008). Reindeer herbivory reduces willow growth and grouse forage in a forest-tundra ecotone.Basic Appl. Ecol. , 9, 324-331.

Hoch, G. \& Korner, C. (2003). The carbon charging of pines at the climatic treeline: a global comparison. Oecologia , 135, 10-21.

Hoogesteger, J., \& Karlsson, P. S. (1992). Effects of defoliation on radial stem growth and photosynthesis in the mountain birch (Betula pubescens ssp. tortuosa). Funct. Ecol. , 6, 317-323.

Hsieh, C. H., Anderson, C., \& Sugihara, G. (2008). Extending nonlinear analysis to short ecological time series. Am. Nat. , 171, 71-80.

Jepsen, J. U., Hagen, S. B., Ims, R. A., \& Yoccoz, N. G. (2008). Climate change and outbreaks of the geometrids Operophtera brumata and Epirrita autumnata in subarctic birch forest: evidence of a recent outbreak range expansion. J. Anim. Ecol. , 77, 257-264.

Karakoc, C., Clark, A. T. \& Chatzinotas, A. (2020). Diversity and coexistence are influenced by timedependent species interactions in a predator-prey system. Ecol. Lett. , in press

Kitti, H., Forbes, B. C., \& Oksanen, J. (2009). Long-and short-term effects of reindeer grazing on tundra wetland vegetation. Polar Biol. , 32, 253-261.

Lehmann, P., Ammunet, T., Barton, M., Battisti, A., Eigenbrode, S. D., et al . (2020). Complex responses of global insect pests to climate warming. Front. Ecol. Env., in press

Lund, M., Raundrup, K., Westergaard-Nielsen, A., Lopez-Blanco, E., Nymand, J., et al . (2017). Larval outbreaks in West Greenland: instant and subsequent effects on tundra ecosystem productivity and $\mathrm{CO}_{2}$ exchange. Ambio , 46, 26-38.

Marshall, K. N., Cooper, D. J., \& Hobbs, N. T. (2014). Interactions among herbivory, climate, topography and plant age shape riparian willow dynamics in northern Yellowstone National Park, USA. J. Ecol. , 102, 667-677.

Martin, A. C., Jeffers, E. S., Petrokofsky, G., Myers-Smith, I., \& Macias-Fauria, M. (2017). Shrub growth and expansion in the Arctic tundra: an assessment of controlling factors using an evidence-based approach. Env. Res. Lett. , 12, 085007.

Massad, T. J. (2013). Ontogenetic differences of herbivory on woody and herbaceous plants: a meta-analysis demonstrating unique effects of herbivory on the young and the old, the slow and the fast.Oecologia , 172, $1-10$.

Mohammed, A.-R. \& Tarpley, L. (2009). Impact of High Nighttime Temperature on Respiration, Membrane Stability, Antioxidant Capacity, and Yield of Rice Plants. Crop Sci. , 49, 313-322.

Myers-Smith, I. H., Elmendorf, S. C., Beck, P. S., Wilmking, M., Hallinger, M., et al . (2015). Climate sensitivity of shrub growth across the tundra biome. Nature Clim. Ch. , 5, 887-891.

Newton, E. J., Pond, B. A., Brown, G. S., Abraham, K. F., \& Schaefer, J. A. (2014). Remote sensing reveals long-term effects of caribou on tundra vegetation. Polar Biol. , 37, 715-725. 
O'Connor, M. I. (2009). Warming strengthens an herbivore-plant interaction. Ecology, 90, 388-398.

Olofsson, J., Oksanen, L., Callaghan, T., Hulme, P. E., Oksanen, T., et al . (2009). Herbivores inhibit climate-driven shrub expansion on the tundra. Glob. Ch. Biol. , 15, 2681-2693.

Pajunen, A. M. (2009). Environmental and biotic determinants of growth and height of arctic willow shrubs along a latitudinal gradient.Arct. Ant. Alp. Res. , 41, 478-485.

Pajunen, A., Virtanen, R., \& Roininen, H. (2008). The effects of reindeer grazing on the composition and species richness of vegetation in forest-tundra ecotone. Polar Biol. , 31, 1233-1244.

Pajunen, A., Virtanen, R., \& Roininen, H. (2012). Browsing-mediated shrub canopy changes drive composition and species richness in forest-tundra ecosystems. Oikos , 121, 1544-1552.

Post, E., \& Pedersen, C. (2008). Opposing plant community responses to warming with and without herbivores. Proc. Nat. Acad. Sci. , 105, 12353-12358.

Ravolainen, V. T., Brathen, K. A., Ims, R. A., Yoccoz, N. G., Henden, J. A., et al. (2011). Rapid, landscape scale responses in riparian tundra vegetation to exclusion of small and large mammalian herbivores.Basic Appl. Ecol. , 12, 643-653.

Ravolainen, V. T., Brathen, K. A., Yoccoz, N. G., Nguyen, J. K., \& Ims, R. A. (2014). Complementary impacts of small rodents and semi-domesticated ungulates limit tall shrub expansion in the tundra.J. Appl. Ecol. , 51, 234-241.

Ren, P., Neron, V., Rossi, S., Liang, E., Bouchard, M., et al . (2020). Warming counteracts defoliationinduced mismatch by increasing herbivore-plant phenological synchrony. Glob. Ch. Biol., in press

Roy, B. A., Gusewell, S., \& Harte, J. (2004). Response of plant pathogens and herbivores to a warming experiment. Ecology, 85, 2570-2581.

Seidl, R., Thom, D., Kautz, M., Martin-Benito, D., Peltoniemi, M., et al . (2017). Forest disturbances under climate change. Nature Clim. Ch. , 7, 395-402.

Sugihara, G. (1994). Nonlinear Forecasting for the Classification of Natural Time-Series. Phil. Trans. $R$. Soc. A: Mathem. Phys. Engin. Sci. , 348, 477-95.

Sugihara, G., May, R., Ye, H., Hsieh, C. H., Deyle, E., et al . (2012). Detecting causality in complex ecosystems. Science, 338, 496-500.

Svensson, B. M., Carlsson, B. A., \& Melillo, J. M. (2018). Changes in species abundance after seven years of elevated atmospheric $\mathrm{CO} 2$ and warming in a subarctic birch forest understorey, as modified by rodent and moth outbreaks. PeerJ , 6, e4843.

Takahashi, M., \& Huntly, N. (2010). Herbivorous insects reduce growth and reproduction of big sagebrush (Artemisia tridentata).Arthropod-Plant Interactions , 4, 257-266.

Tape, K. D., Lord, R., Marshall, H. P., \& Ruess, R. W. (2010). Snow-mediated ptarmigan browsing and shrub expansion in arctic Alaska.Ecoscience , 17, 186-193.

Tenow, O., Bylund, H., Karlsson, P. S., \& Hoogesteger, J. (2004). Rejuvenation of a mountain birch forest by an Epirrita autumnata (Lepidoptera: Geometridae) outbreak. Acta Oecol. , 25, 43-52.

Trotter, R. T., Cobb, N. S., \& Whitham, T. G. (2002). Herbivory, plant resistance, and climate in the tree ring record: Interactions distort climatic reconstructions. Proc. Nat. Acad. Sci. , 99, 10197-10202.

Virtanen, R., Oksanen, L., Oksanen, T., Cohen, J., Forbes, B. C., et al . (2016). Where do the treeless tundra areas of northern highlands fit in the global biome system: toward an ecologically natural subdivision of the tundra biome. Ecol. Evol. , 6, 143-158. 
Vuorinen, K. E., Rao, S. J., Hester, A. J., \& Speed, J. D. (2020). Herbivory and climate as drivers of woody plant growth: Do deer decrease the impacts of warming?. Ecol. Appl. , in press

Weijers, S., Buchwal, A., Blok, D., Loffler, J., \& Elberling, B. (2017). High Arctic summer warming tracked by increased Cassiope tetragona growth in the world's northernmost polar desert. Glob. Ch. Biol. , 23, $5006-5020$.

Weijers, S., Beckers, N., \& Loffler, J. (2018). Recent spring warming limits near-treeline deciduous and evergreen alpine dwarf shrub growth.Ecosphere , 9, e02328.

Wijk, S. (1986). Influence of climate and age on annual shoot increment in Salix herbacea. J. Ecol. , 74, 685-692.

Wilmking, M., Hallinger, M., Van Bogaert, R., Kyncl, T., Babst, F., et al . (2012). Continuously missing outer rings in woody plants at their distributional margins. Dendrochronol. , 30, 213-222.

Wilmking, M., Buras, A., Lehejček, J., Lange, J., Shetti, R., et al . (2018). Influence of larval outbreaks on the climate reconstruction potential of an Arctic shrub. Dendrochronol. , 49, 36-43.

Ye, H., Clark, A.T., Deyle, E., Munch, S., Keyes, O., et al . (2018). REDM: Applications of empirical dynamic modeling from time series. Zenodo. https://doi.org/10.5281/ZENODO.1294063. 